\title{
Low Temperature Synthesis of Mixed Phase Titania Nanoparticles with High Yield, its Mechanism and Enhanced Photoactivity
}

\author{
Prapti Chaudhari", Vijay Chaudharia and Satyendra Mishra ${ }^{a *}$ \\ ${ }^{a}$ University Institute of Chemical Technology, North Maharashtra University, Jalgaon, MS 425001, India
}

Received: November 17, 2015; Accepted: January 18, 2016

\begin{abstract}
A novel process was developed for the synthesis of a mixed phase (constituted of $66 \%$ anatase phase) of $\mathrm{TiO}_{2}$ nanoparticles at lower calcination temperature $\left(400{ }^{\circ} \mathrm{C}\right)$ by the sol gel technique using a cost effective and easily available propanol solvent. Stereochemistry of propanol played a crucial role towards crystallographic phase of resultant $\mathrm{TiO}_{2}$ nanoparticles where n-propanol gave mixed phase while i-propanol gave pure anatase. A plausible mechanism has been proposed. An effect of crystallographic phase on their photocatalytic activity was studied using degradation of bromophenol blue dye. The rate constants of the dye degradation reaction for anatase phase and mixed phase were found to be $6.86 \times 10^{-3} / \mathrm{s}$ and $1.56 \times 10^{-2} / \mathrm{s}$ respectively. A mixed phase of $\mathrm{TiO}_{2}$ showed faster (120 min for $84 \%$ ) photodegradation compared to the anatase phase (270 min. for $84 \%$ ) due to an effect of crystalline and electronic parameters. The cyclic voltammetry results depicted the reducing nature of $\mathrm{i}-\mathrm{TiO}_{2}$ than $\mathrm{n}-\mathrm{TiO}_{2}$, which creates unfavorable situation for the electron transfer from $\mathrm{TiO}_{2}$ to dye.
\end{abstract}

Keywords: Semiconductor, Nanoparticles, Sol gel method, Low calcination temperature, Photodegradation

\section{Introduction}

$\mathrm{TiO}_{2}$ is the most studied metal oxide nano-material due to its excellent photochemical performance, low cost, stability and availability ${ }^{1,2}$. Its performance can be improved by tuning the size as well as crystallographic phase ${ }^{3}$. There are different polymorphs of $\mathrm{TiO}_{2}$ like anatase, rutile, brookite and $\mathrm{TiO}_{2} \mathrm{~B}^{2,4}$. Amongst which the anatase phase is meta-stable bearing the highest band gap energy and has a wide applications in different fields ${ }^{5-7}$. It is reported ${ }^{8-11}$ that mixed phase of anatase and rutile $\mathrm{TiO}_{2}$ show more favourable photocatalytic properties due to transfer of electrons from anatase to rutile phase, which reduces the recombination rate of anatase, leading to more efficient electron-hole separation and greater catalytic reactivity ${ }^{12}$. Owing to these facts, many researchers synthesized mixed phase of $\mathrm{TiO}_{2}{ }^{8-11}$, but it is energy intensive. Hence, under these studies, the titania nanoparticles were synthesized using a common solvent at low temperature using sol-gel method.

\section{Experimental}

\subsection{Materials}

All the chemicals used were of high purity (AR grade). The titanium (IV) isopropoxide $98 \%$ was used as a precursor (Avra synthesis, Hyderabad) while isopropanol and $n$-propanol were used as solvent (Qualigens, Mumbai). All the chemicals were used without further purifications.

Solutions were prepared using double distilled water.

*e-mail: profsm@rediffmail.com

\subsection{Synthesis of $\mathrm{TiO}_{2}$ nanoparticles}

A pure anatase phase and mixed phase of $\mathrm{TiO}_{2}$ were synthesized by modifying the protocol of Hemissi and Adnani ${ }^{13}$. Titanium isopropoxide was mixed with isopropanol as solvent in the ratio of $1: 3$ with total volume of $6 \mathrm{~mL}$ and was stirred at $60^{\circ} \mathrm{C}$ in a closed borosilicate glass container for $10 \mathrm{~min}$. Subsequently, $5 \mathrm{~mL}$ of acetic acid was added with vigorous stirring and kept for $15 \mathrm{~min}$ at the same temperature. Further, $12 \mathrm{~mL}$ of isopropanol was added and agitated for $2 \mathrm{~h}$. The resultant sol was heated at $100^{\circ} \mathrm{C}$ in the hot air oven to evaporate the solvent. The dried gel was annealed in muffle furnace at $400{ }^{\circ} \mathrm{C}$ for $2 \mathrm{~h}$. The product obtained was named as $i-\mathrm{TiO}_{2}$. Similar procedure was repeated using $n$-propanol as solvent and resultant product was named as $n-\mathrm{TiO}_{2}$.

\subsection{Characterization of materials}

The crystal structure and size of synthesized material were confirmed using the Field emission gun transmission electron microscopy (FEG-TEM, Jeol, JEM-2100F, Tokyo, Japan, resolution $0.19 \mathrm{~nm}, 200 \mathrm{kV}$ ). Crystallographic phase, crystallite size and relative phase composition were determined using Advance X-ray diffractometer (Bruker D8, Karlsruhe, Germany) with $\mathrm{CuK} \alpha_{1}$ radiation $(\lambda=1.5404 \AA)$ within the $2 \theta$ range of $20-80^{\circ}$.

Band structure of the nano-materials was determined using spectrofluorometer (Shimadzu RF5301PC, Kyoto, Japan). Emission spectra were recorded at an excitation wavelength of $320 \mathrm{~nm}$. Redox behaviours of $n-\mathrm{TiO}_{2}$ and $i-\mathrm{TiO}_{2}$ were investigated through metro-ohm PGSTAT/Galvanostat-100 
(Utrecht, The Netherlands). Typically, three electrode systems contain $\mathrm{TiO}_{2}$ drop-casted on ITO plate as working electrode, platinum wire and $\mathrm{Ag} / \mathrm{AgCl}$ as counter and reference electrode respectively with $0.1 \mathrm{M}$ aqueous $\mathrm{NaClO}_{4}$ electrolyte.

\subsection{Photocatalytic Activity}

The photocatalytic activity of $i-\mathrm{TiO}_{2}$ and $n-\mathrm{TiO}_{2}$ was evaluated using degradation of the bromophenol blue aqueous solution under illumination of UV light (G8T5 Sankyo Denki, UV C). The $\mathrm{TiO}_{2}$ nanoparticles ( $\left.5 \mathrm{~g} / \mathrm{L}\right)$ were added into the quartz flask containing $100 \mathrm{~mL}$ aqueous solution of the dye (50 ppm). The prepared suspension was magnetically stirred for half an hour in dark to achieve the adsorption equilibrium. $3 \mathrm{~mL}$ aliquot was taken as a blank solution before irradiation. It was centrifuged to settle the catalyst and the supernatant was analysed by UV-visible spectrophotometer (Agilent technologies, Cary 60, California, USA). Afterward, the suspension was illuminated by a UV lamp until decolourization of the dye occurred. The progress of the reaction was followed by recording the absorbance at 30 min time interval. The degradation of bromophenol blue was calculated using the formula: \%degradation $=\left(A_{0}-A\right) / A_{0}$, where $\mathrm{A}_{0}$ and $\mathrm{A}$ are absorbance of the primal and remaining dye respectively. The rate of reaction was calculated from the graph of $1+\log \mathrm{A}$ vs. time for $i-\mathrm{TiO}_{2}$ and $n-\mathrm{TiO}_{2}$ using the expression; $k=2.303 \times$ slope.

\section{Results and Discussion}

Spherical morphology with an average size $c a .10 \mathrm{~nm}$ and $12 \mathrm{~nm}$ for $i-\mathrm{TiO}_{2}$ and $n-\mathrm{TiO}_{2}$ respectively was observed from the FEG-TEM images (Fig. 1). For both $i-\mathrm{TiO}_{2}$ and $n-\mathrm{TiO}_{2}$, PL peak (Fig. 2 ) was observed at nearly same wavelength. Band gap of anatase phase $(3.2 \mathrm{eV})$ was higher than the mixed phase $(3 \mathrm{eV})$ and hence PL spectra for the anatase phase are expected at lower wavelength than mixed phase. However, comparatively smaller band gap for mixed phase is attributed to the larger particle size.

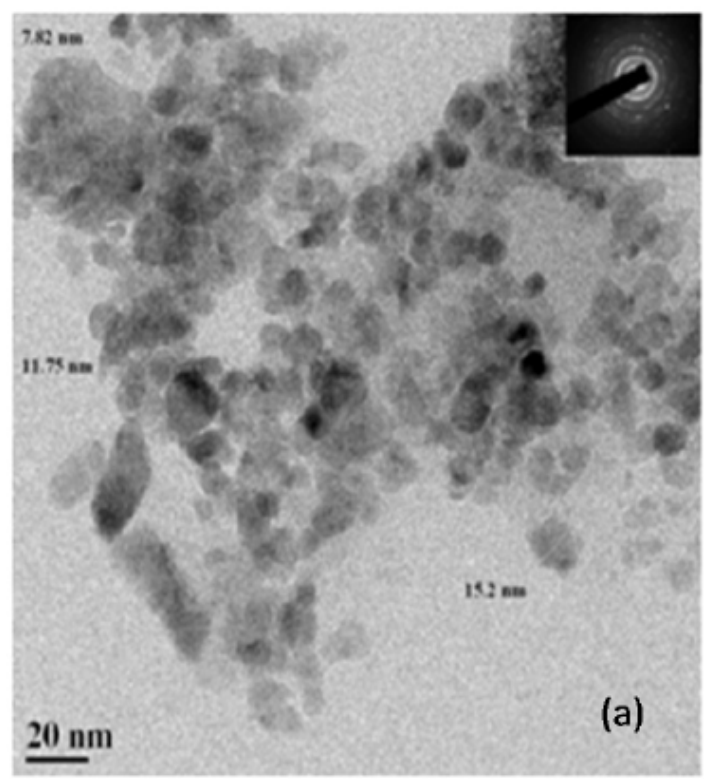

The synthesized nanoparticles subjected to XRD analysis (Fig. 3) showed the typical XRD pattern of $i-\mathrm{TiO}_{2}$ and $n-\mathrm{TiO}_{2}$. All the detected diffraction peaks in the $i-\mathrm{TiO}_{2}$ pattern were assigned to the anatase phase (JCPDS No. PDF-21-1272). Prominent reflections at $2 \theta$ values, $27.4^{\circ}, 35.8^{\circ}, 40.9^{\circ}$ for $n-\mathrm{TiO}_{2}$ were indexed as [110], [101], [111] planes of rutile phase of $\mathrm{TiO}_{2}$ (JCPDS No. PDF-01-72-7374). The crystallite size of $i-\mathrm{TiO}_{2}$ and $n-\mathrm{TiO}_{2}$ was estimated to be $17 \mathrm{~nm}$ and $24 \mathrm{~nm}$, respectively from the reflection planes [105] and [101] data using the Debye Scherrer's equation ${ }^{14}$. The relative phase composition of rutile in $n-\mathrm{TiO}_{2}$ was found to be $66 \%$ which was calculated using Spurr and Myers formula ${ }^{15}$.

An observed variation in crystallographic phase for $i-\mathrm{TiO}_{2}$ and $n-\mathrm{TiO}_{2}$ is explained on the basis of proposed model given in Fig 4. In the sol gel method, formation of metal oxide nanoparticles generally occurs through hydrolysis and condensation reactions of metal alkoxide. Transition metal alkoxides are strong Lewis acids and hence; their hydrolysis occurs through proton assisted $\mathrm{S}_{\mathrm{N}} 1$ mechanism ${ }^{16,17}$; rather than $\mathrm{S}_{\mathrm{N}} 2$ mechanism ${ }^{18}$. Moreover, presence of highly electronegative isopropoxide (OiPr) groups stabilizes the titanium metal in its highest oxidation state and is also able to form a stable cationic complex. All these facts are supportive for the hydrolysis reaction through $\mathrm{H}^{+}$assisted $\mathrm{S}_{\mathrm{N}} 1$ mechanism. Isopropanol and $n$-propanol are polar protic solvents with different proton donating ability driven by their structure, and hence; they can influence the $\mathrm{S}_{\mathrm{N}} 1$ mechanism steps involved in $\mathrm{TiO}_{2}$ formation.

Under the influence of $\mathrm{H}^{+}$, the Ti-OiPr bond breaks into $\left[\mathrm{Ti}-(\mathrm{OiPr})_{3}\right]^{+}$and [OiPr] - followed by nucleophilic attack of propanol on electron deficient $\left[\mathrm{Ti}-(\mathrm{OiPr})_{3}\right]^{+}$releasing propyl cations. Successively, all OiPr groups get exchanged with $\mathrm{OH}$ that results into $\mathrm{Ti}(\mathrm{OH})_{4}$. The final condensation step involves the dehydration of $\mathrm{Ti}(\mathrm{OH})_{4}$ to $\mathrm{TiO}_{2}$. However, the next step is the rate determining step of overall mechanism, where stereochemistry of isopropanol and $n$-propanol controls the nature of final product. Secondary cations generated

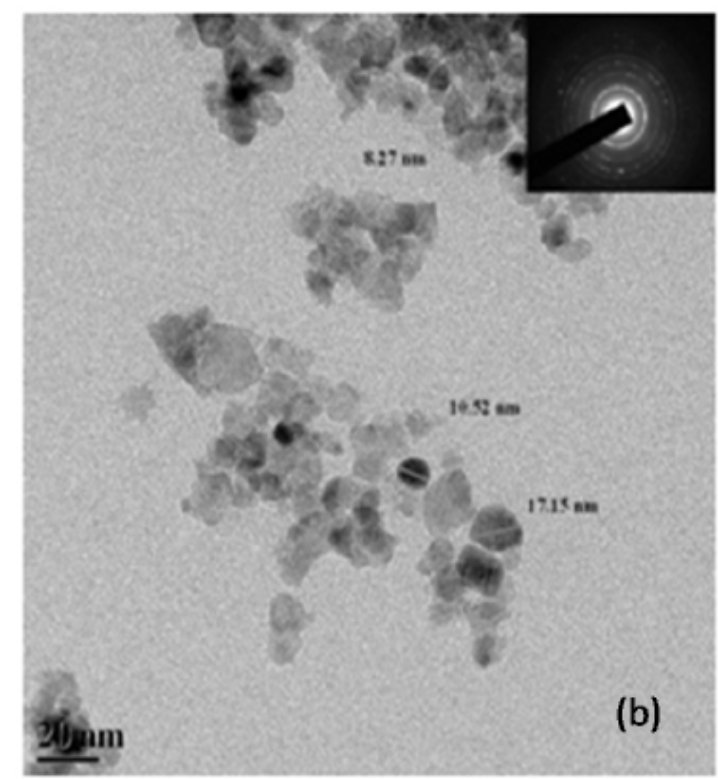

Fig. 1 FEG-TEM images of (a) $i$ - $\mathrm{TiO}_{2}$ and (b) $n-\mathrm{TiO}_{2}$ 
from isopropanol has greater stability due to the inductive effect $(+\mathbf{I})$, than primary cations generated from $n$-propanol, and can enhance the kinetics of overall reaction. Secondly, length of isopropanol is smaller than the $n$-propanol, which can affect the bond length/ orientation in Ti-O-Ti three

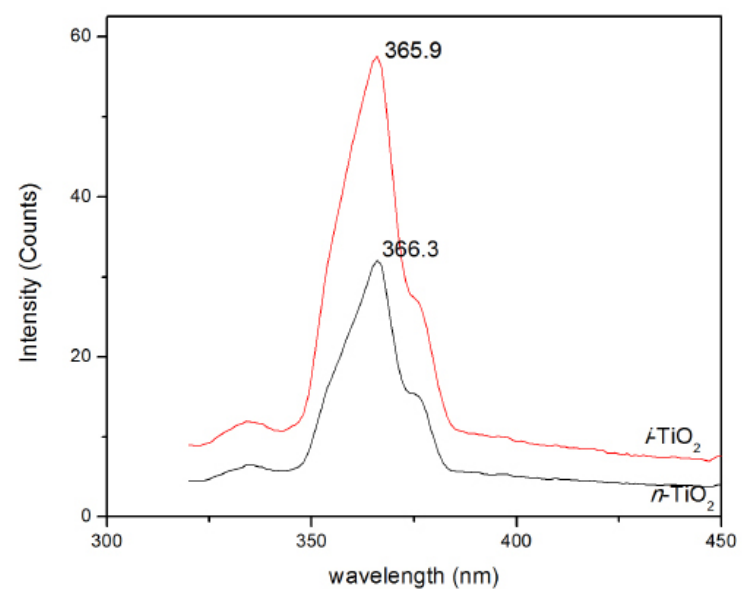

Fig. 2 Photoluminescence spectra of $n-\mathrm{TiO}_{2}$ and $i-\mathrm{TiO}_{2}$ nanoparticles

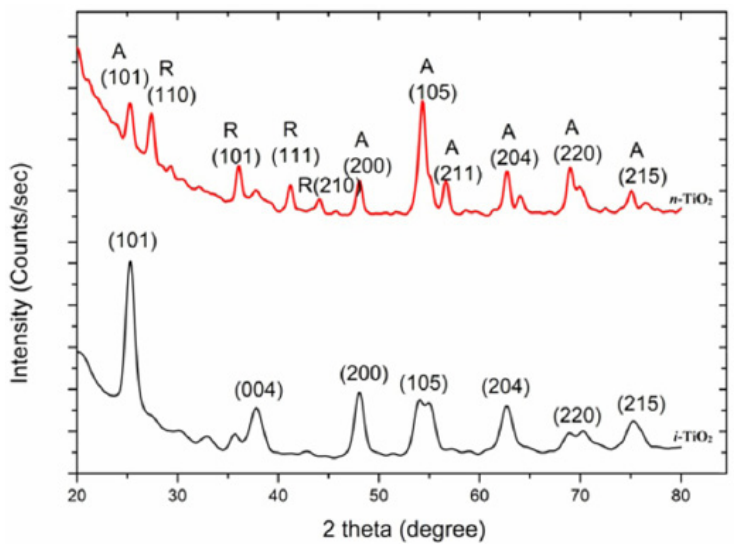

Fig. 3 XRD spectra of (a) $i-\mathrm{TiO}_{2}$ and (b) $n-\mathrm{TiO}_{2}$ (with * exhibiting rutile phase) dimensional networks. Interestingly, comparable trend of Ti-O bond lengths in anatase $\left(1.937 \mathrm{~A}^{\circ}\right)$ and rutile $\left(1.949 \mathrm{~A}^{\circ}\right)$ with size of isopropanol and $n$-propanol suggest that the observed variation in crystallographic phase of $n-\mathrm{TiO}_{2}$ and $i$-TiO 2 may be due to the size and stereochemistry of solvent.

A significant difference was observed in the electrochemical response of $n-\mathrm{TiO}_{2}$ and $i-\mathrm{TiO}_{2}$ recorded in cyclic voltammogram (Fig. 5). In case of $n-\mathrm{TiO}_{2}$, no peaks were observed; while $i$ - $\mathrm{TiO}_{2}$ showed cathodic peak at $0.24 \mathrm{~V}$. $\mathrm{TiO}_{2}$ is n-type semiconductor and hence expected to show anodic peak rather cathodic. Moreover, the peak current was found to be increased with successive scans and saturates thereafter. The observed discrepancy can be attributed to the reduction of $\mathrm{Ti}^{4+}$ to $\mathrm{Ti}^{3+}$ as per the reaction I given below.

$\mathrm{TiO}_{2}+\mathrm{e}+4 \mathrm{H}^{+} \rightarrow \mathrm{Ti}^{3+}+2 \mathrm{H}_{2} \mathrm{O}$

Therefore; $n-\mathrm{TiO}_{2}$ and $i-\mathrm{TiO}_{2}$ showed different redox behaviour, which may be due to the variation in crystallographic phase. The $i-\mathrm{TiO}_{2}$ showed more reducing tendency than $n-\mathrm{TiO}_{2}$.

The photo-degradation of bromophenol blue dye with $i-\mathrm{TiO}_{2}$ and $n-\mathrm{TiO}_{2}$ as catalyst was studied. The variations in percent dye degradation could be observed (Fig. 6) as determined from the absorbance value at $\lambda_{\max }(592 \mathrm{~nm})$ of UV-visible spectra with respect to reaction time. About $84 \%$ degradation was obtained within 120 min with $n$-TiO; ; whereas $i$ - $\mathrm{TiO}_{2}$ required $270 \mathrm{~min}$ to achieve the similar degradation, which was in agreement with that reported in the literature ${ }^{8-11}$. Thus the mixed phase of $\mathrm{TiO}_{2}\left(n-\mathrm{TiO}_{2}\right)$ nanoparticles showed the higher photo-catalytic activity than $i-\mathrm{TiO}_{2}$ The plot of $1+\log$ A v/s time, shown in Fig.7, is linear suggesting the pseudo- first order reaction kinetics. The rate constants of the dye degradation reactions in presence of $i-\mathrm{TiO}_{2}$ and $n$ - $\mathrm{TiO}_{2}$, determined from the slope of Fig. 7 were found to be $6.86 \times 10^{-3} / \mathrm{s}$ and $1.56 \times 10^{-2} / \mathrm{s}$ respectively.

The photo-catalytic activity of $\mathrm{TiO}_{2}$ depends on band edge positions, crystallographic phase and interaction mechanism with guest moieties. In present investigation, band gap energies of both the samples are almost similar and hence it is worth to pursue an effect of crystalline and electronic parameters on their photo-catalytic behavior. The cyclic voltammetry results depicted the reducing nature of $i-\mathrm{TiO}_{2}$ than $n-\mathrm{TiO}_{2}$ which creates unfavorable situation for the electron transfer

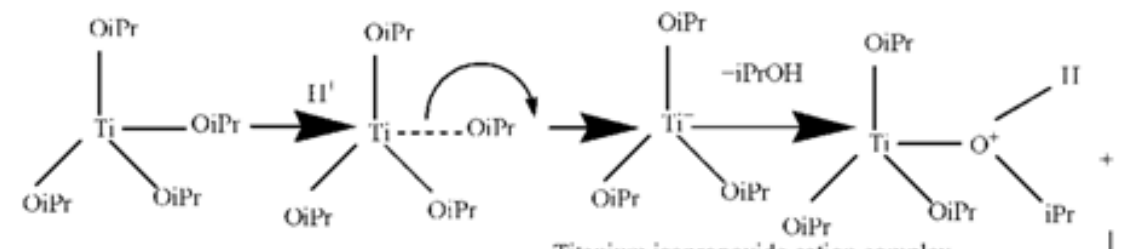

Titanium isopropoxide Titanium isopropoxide cation complex

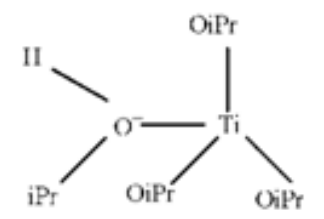
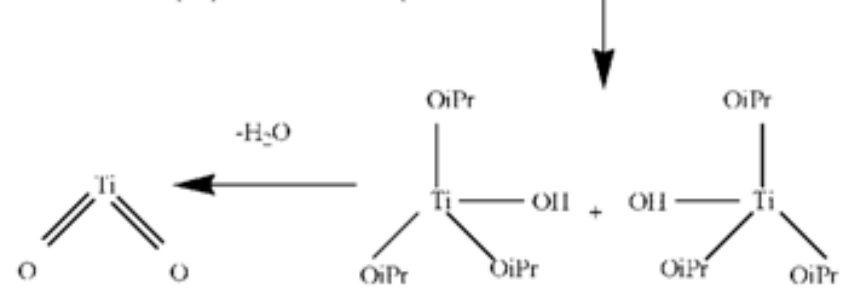

Fig. 4 Proton assisted $\mathrm{S}_{\mathrm{N}} 1$ reaction for synthesis of $\mathrm{TiO}_{2}$ 


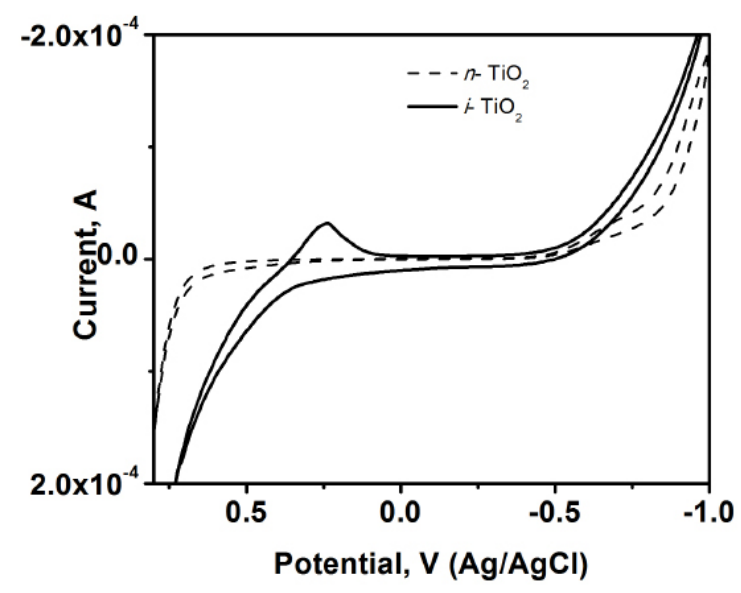

Fig. 5 Cyclic voltammogram of nanosized $i-\mathrm{TiO}_{2}$ and $n-\mathrm{TiO}_{2}$

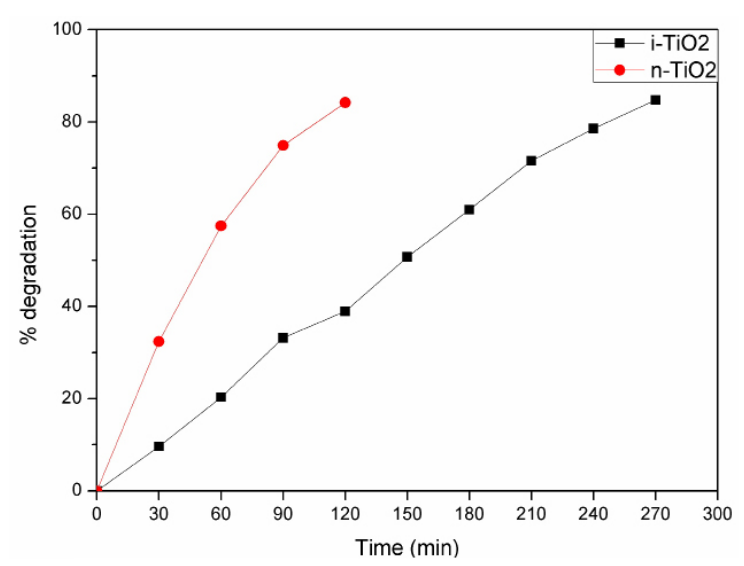

Fig. 6 Percent degradation of bromophenol blue dye by $i-\mathrm{TiO}_{2}$ and $n$ - $\mathrm{TiO}_{2}$ nanoparticles from $\mathrm{TiO}_{2}$ to dye. Secondly, Mercado et al., ${ }^{19}$ systematically showed that stoichiometric variation in rutile and anatase (or mixed) phase of $\mathrm{TiO}_{2}$ affects the electron transfer ability and hence its photo-catalytic activity. The observed variations in $n-\mathrm{TiO}_{2}$ and $i-\mathrm{TiO}_{2}$ have been attributed to the variation in their redox behavior (ie. $n$-TiO2 is less or not reducing in nature, which helps to make available the electrons for activity). Also the stoichiometric variation (position of oxygen from $\mathrm{TiO}_{2}$ ) decides the nature of interaction between $\mathrm{TiO}_{2}$ and dye found to be favorable in mixed phase than pure anatase phase.

Another important observation was noticed about the phase transformation from anatase to rutile that occurred at annealing temperature ranging from $600{ }^{\circ} \mathrm{C}$ to $1100{ }^{\circ} \mathrm{C}$, probably depending mainly on the impurities present in the anatase phase ${ }^{20}$. Many researchers have synthesized a mixed phase of $\mathrm{TiO}_{2}{ }^{8-11}$. A comparison of that is given in Table 1; however the method reported in present work is simple, cost effective with less consumption of heat energy and time for curing.

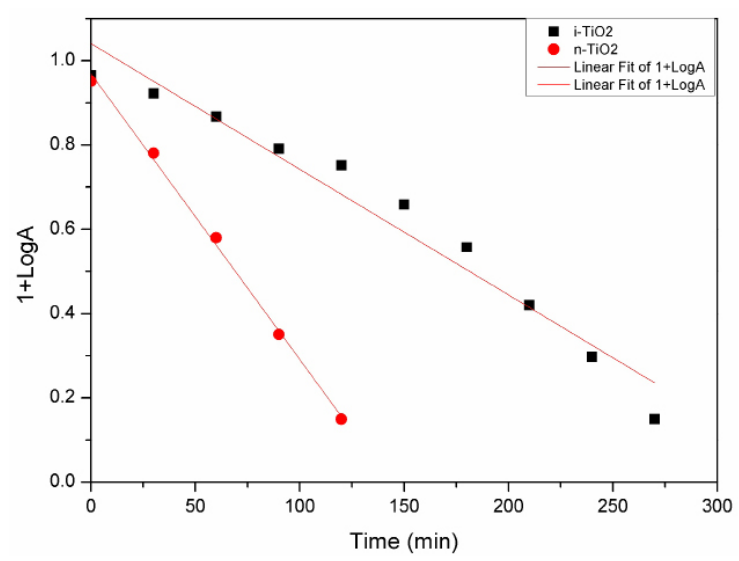

Fig.7 Graph of $1+\log$ A versus time for $n-\mathrm{TiO}_{2}$ and $\mathrm{i}-\mathrm{TiO}_{2}$ nanoparticles

Table 1. Relative comparison of reaction parameters of some research work

\begin{tabular}{|c|c|c|c|c|c|}
\hline $\begin{array}{l}\text { Reference } \\
\text { No. }\end{array}$ & $\begin{array}{l}\text { Starting } \\
\text { material }\end{array}$ & $\begin{array}{c}\text { Other materials } \\
\text { used }\end{array}$ & $\begin{array}{l}\text { Reaction temperature } \\
\text { and time }\end{array}$ & $\begin{array}{l}\text { Calcination } \\
\text { temperature } \\
\text { and time }\end{array}$ & Remarks \\
\hline 8 & $\begin{array}{l}\text { titanium } \\
\text { isopropoxide }\end{array}$ & $\begin{array}{c}\text { ethanol, } \\
\text { hydrochloric } \\
\text { acid }\end{array}$ & $\begin{array}{l}\text { Reaction temperature: } \\
60^{\circ} \mathrm{C} \text { for } 5 \mathrm{~h} \\
\text { Drying temperature: } \\
50^{\circ} \mathrm{C} \text { till completely } \\
\text { dried }\end{array}$ & $500^{\circ} \mathrm{C}$ for $24 \mathrm{~h}$ & high temperature and more time \\
\hline 9 & $\mathrm{TiCl}_{4}, \mathrm{Ti}\left(\mathrm{OC}_{2} \mathrm{H}_{5}\right)_{4}$ & $\begin{array}{l}\text { ice cold water, } \\
\text { dry ethanol }\end{array}$ & $\begin{array}{c}\text { Aging time } 2 \mathrm{~h} \\
\left.\text { (for } \mathrm{TiCl}_{4}\right) \text { and } 25 \mathrm{~min} \\
\left(\text { for } \mathrm{Ti}\left(\mathrm{OC}_{2} \mathrm{H}_{5}\right)_{4}\right) \\
\text { Drying time } 24 \mathrm{~h}\end{array}$ & $\begin{array}{l}\text { above } 800^{\circ} \mathrm{C} \text { for } \\
24 \mathrm{~h}\end{array}$ & $\begin{array}{l}\text { use of expensive dry ethanol high } \\
\text { calcination temperature and time. } \\
\text { Method includes centrifugation, } \\
\text { washing and drying. }\end{array}$ \\
\hline 10 & $\mathrm{TiOSO}_{4}$ & $\begin{array}{l}\text { acidic water, } \\
\text { HSO4 urea, pH } \\
\text { controllers }\end{array}$ & $\begin{array}{l}\text { Reaction temperature: } \\
100^{\circ} \mathrm{C} \text { for } 6 \mathrm{~h}\end{array}$ & $\begin{array}{c}850^{\circ} \mathrm{C} \text { for } 3 \mathrm{~h} \\
\text { at heating rate } \\
10^{\circ} \mathrm{C} / \mathrm{min}\end{array}$ & $\begin{array}{l}\text { high calcination temperature and } \\
\text { more time }\end{array}$ \\
\hline 11 & $\begin{array}{l}\text { tetra butyl } \\
\text { titanate }\end{array}$ & $\begin{array}{l}\text { acetyl acetone, } \\
\text { alcohol, } \\
\text { laurylamine } \\
\text { hydrochloride }\end{array}$ & $\begin{array}{c}\text { Reaction temperature } \\
40^{\circ} \mathrm{C} \text { for } 2 \mathrm{~h} \\
\text { Aging and drying } \\
\text { temperatures } 80^{\circ} \mathrm{C} \text { each } \\
\text { with aging time for } 72 \mathrm{~h}\end{array}$ & $\begin{array}{l}500{ }^{\circ} \mathrm{C} \text { for } 2 \mathrm{~h} \\
\text { with heating rate } \\
\text { maintained as } \\
5 \mathrm{~K} / \mathrm{min} \text {. }\end{array}$ & $\begin{array}{l}\text { use of laurylamine, total } \\
\text { synthesis time is large }\end{array}$ \\
\hline
\end{tabular}




\section{Conclusions}

A mixed phase of anatase and rutile $\mathrm{TiO}_{2}$ nanoparticles was synthesized at low calcination temperature. The variation in crystallographic phase of $\mathrm{TiO}_{2}$ could be attributed to the size and stereochemistry difference between the $n$-propanol and isopropanol. Anatase phase of $\mathrm{TiO}_{2}$ showed less reduction tendency than mixed phase of $\mathrm{TiO}_{2}$. An effect of crystallographic phase on photo-catalytic activity of $i-\mathrm{TiO}_{2}$ and $n-\mathrm{TiO}_{2}$ was investigated using them as catalyst for photo-degradation of bromophenol blue dye. $120 \mathrm{~min}$. were

\section{References}

1. Hashimoto $\mathrm{K}$, Irie $\mathrm{H}$, Fujishima $\mathrm{A}$. $\mathrm{TiO}_{2}$ photocatalysis: $\mathrm{A}$ historical overview and future prospects, Japanese Journal of Applied Physics. 2005;44(12):8269-8285. https://www.jsap. or.jp/jsapi/Pdf/Number14/04_JJAP-IRP.pdf

2. Gupta SM, Tripathi M. A review of $\mathrm{TiO}_{2}$ nanoparticles, Chinese Science Bulletin. 2011;56(16):1639-1657.

3. Ruan P, Qian J, Su Y, Sie h, Shao C, Zhou X. Mixed-phase $\mathrm{TiO}_{2}$ nanorods assembled microsphere: crystal phase control and photovoltaic application, CrystEngComm. 2013;15:50935099. DOI: $10.1039 / \mathrm{C} 3 \mathrm{CE} 40351 \mathrm{C}$

4. Carp O, Huisman C, Reller A. Photoinduced reactivity of titanium dioxide, Progress in Solid State Chemistry. 2004,32(12):33-117.

5. Mardare D, Tasca M, Delibas M, Rusu G. On the structural properties and optical transmittance of $\mathrm{TiO}_{2} \mathrm{RF}$ sputtered thin films. Applied Surface Science. 2000;156(1-4):200-206.

6. Di Paola A, Bellardita M, Ceccato R, Palmisano L, Parrino F. Highly active photocatalytic $\mathrm{TiO}_{2}$ powders obtained by thermohydrolysis of $\mathrm{TiCl}_{4}$ in water. The Journal of Physical Chemistry C. 2009;113(34):15166. DOI: 10.1021/jp904673e

7. Wang Y, Lu L, Yang H, Che Q. Development of high dispersed $\mathrm{TiO}_{2}$ paste for transparent screen- printable self cleaning coatings on glass. Journal Of Nanoparticles Research. 2013;15:1384. DOI: 10.1007/s11051-012-1384-5

8. Addamo M, Augugliaro V, Di Paola A, Garcia-Lopez E, Loddo V, Marci G, et al. Preparation, characterization and photoactivity of polycrystalline nanostructured $\mathrm{TiO}_{2}$ catalysts. Journal of Physics Chemistry B. 2004;108:3303-3310.

9. Ovenstone J, Yanagisawa K. Effect of hydrothermal treatment of amorphous titania on the phase change from anatase to rutile during calcinations. Chemistry of Materials. 1999;11(10):27702774. DOI: $10.1021 / \mathrm{cm} 990172 \mathrm{z}$

10. Bakardjieva S, Subrt J, Stengl V, Dianez M, Sayagues M. Photoactivity of anatase-rutile $\mathrm{TiO}_{2}$ nanocrystalline mixtures obtained by heat treatment of homogeneously precipitated anatase, Journal Catalysis: Environmental. 2005;58(3-4):193202.

11. You X, Chen F, Zhang J. Effects of calcination on the physical and photocatalytic properties prepared by sol-gel template method. required by $n-\mathrm{TiO}_{2}$ and $270 \mathrm{~min}$ by $i-\mathrm{TiO}_{2}$ to degrade $84 \%$ of bromophenol dye. The higher photo-catalytic activity of $n-\mathrm{TiO}_{2}$ than $i-\mathrm{TiO}_{2}$ was due to its less reducing tendency.

\section{Acknowledgement}

The author Satyendra Mishra acknowledges the financial support from University Grants Commission, New Delhi (Project No. F.4-10/2010 (BSR) and Prapti Chaudhari is thankful to Department of Science and Technology, New Delhi for DST-INSPIRE Fellowship (IF 120685).

Journal of Sol-Gel Science and Technology. 2005;34(2):181187.

12. Hurum DC, Agrios AG, Gray KA. Explaining the enhanced photocatalytic activity of Degussa $\mathrm{P} 25$ mixed phase $\mathrm{TiO}_{2}$ using EPR. Journal of Physical Chemistry B. 2003;107(19):45454549. DOI: $10.1021 /$ jp0273934

13. Hemissi M, Aamardjia-Adnani H. Optical and structural properties of titanium oxide thin films prepared by sol gel method. Digest Journal of Nanomaterials and Biostructures. 2007;2(4):299-305. http://www.chalcogen.ro/Hemisi.pdf

14. Dorofeev D, Streletskii A, Povstugar I, Protasov A, Elsukov E. Determination of nanoparticle sizes by X-ray diffraction. Colloid Journal. 2012;74(6):675-685. http://dx.doi.org/10.1134/ S1061933X12060051

15. Spurr RA, Myers H. Quantitative analysis of anatase - rutile mixtures with an X-ray diffractometer. Analytical Chemistry. 1957;29(5):760-762.

16. Kessler V, Spijksma G, Seisenbaeva G, Hakansson S, Dave $\mathrm{H}$, Bouwmeester $\mathrm{H}$. New insight in the role of modifying ligands in the sol-gel processing of metal alkoxide precursors: A possibility to approach new classes of materials. Journal Sol-Gel Science Technologt. 2006;40:163-179. DOI 10.1007/ s10971-006-9209-6

17. Mitsionis A, Vaimakis T. The effect of thermal treatment in $\mathrm{TiO}_{2}$ photocatalytic activity. Journal of Thermal Analysis and Calorimetry. 2013;112(2):621-628. http://link.springer.com/ article/10.1007/s10973-012-2631-9\#page-2

18. Ayres J, Simendinger WH, Balik CM. Characterization of titanium alkoxide sol gel systems designed for anti- icing coatings: I Chemistry. Journal of Coatings Technology and Research. 2007;4(4):463-481.

19. Mercado C, Knorr F, McHale J, Usmani SM, Ichimurav AS, Saraf LV. Location of holes and electron traps on nanocrystalline anatase $\mathrm{TiO}_{2}$. The Journal of Physical Chemistry. 2012;116(19):1079610804. DOI: $10.1021 /$ jp301680d

20. Heald EF, Weiss CW. Kinetics and mechanism of the anatase/ rutile transformation, as catalyzed by ferric oxide and reducing conditions. American Mineralogist. 1972;57:10-23. http://www. minsocam.org/ammin/AM57/AM57_10.pdf 